\title{
IMPLEMENTASI METODE PEMBIASAAN BERBASIS BUDAYA SEKOLAH UNTUK MENINGKATKAN KARAKTER RELIGIUS ANAK BERKEBUTUHAN KHUSUS DI SMPLB-PRI PEKALONGAN
}

\section{Indri Agus Trianis \& Ningsih Fadhilah*}

\begin{abstract}
Abstrack: This research is motivated by the results of preliminary observations in the Pekalongan SMPLB-PRI. Based on what researchers observed the uniqueness of children with special needs, then how their interactions with friends or the surrounding environment, whether the limitations and disadvantages of children with special needs have religious values. From the results of these preliminary observations the researcher took the title of implementing the culture-based habituation method of the school to improve the religious character of children with special needs in Pekalongan High School. The objectives of this study are: 1) To find out the implementation of a school culture-based habituation method to improve the religious character of Children with Special Needs at Pekalongan High School PRI. 2) To find out the obstacles encountered in implementing the culture-based customization method of schools to improve the religious character of Children with Special Needs in Pekalongan High School. This research is a qualitative research type of field research. Data collection methods using interviews, observation and documentation. The data analysis technique used the Miles and Huberman analysis method.
\end{abstract}

Keywords: School Culture Habituation, Religious Character, Children with Special Needs.

* Alumni Jurusan PAI FTIK IAIN Pekalongan 2019, Email: indriagustrianis@gmail.com 


\section{Pendahuluan}

Dendidikan di sekolah erat kaitanya dengan karakter peserta didik, seperti yang sudah diselenggarakan oleh Pemerintah L yaitu Pendidikan Karakter (Religius, Jujur, Toleransi, Cinta Tanah Air, Disiplin, dll), salah satunya adalah karakter religius, sikap dan perilaku yang patuh dalam melaksanakan ajaran agama yang dianutnya, toleran terhadap pelaksanaan ibadah agama lain dan hidup rukun dengan pemeluk agama lain. Pendidikan di sekolah pasti tidak lepas dari budayanya. Budaya sekolah merupakan basis interaksi antara semua anggota masyarakat sekolah yang meliputi nilai-nilai (kepercayaan dan kejujuran), norma-norma (peraturan dan perilaku) yang berlaku dan disepakati oleh semua masyarakat sekolah, serta kebiasaan yang memberikan keunikan atau kekhususan pada sekolah (Barnawi, 2013:109).

Dalam rangka pewujudan budaya sekolah dalam usaha penanaman nilai-nilai religius dihadapkan pada berbagai tantangan baik secara internal maupun eksternal. Secara internal, pendidikan dihadapkan pada keberagaman siswa, baik dari sisi keyakinan agama. Adapun secara eksternal, pendidikan agama dihadapkan pada satu realitas masyarakat yang mengalami krisis moral. Pembudayaan nilai-nilai religius dapat dilakukan beberapa cara, antara lain melalui kebijakan pimpinan sekolah, pelaksanaan kegiatan belajar mengajar dikelas, kegiatan ekstrakulikuler diluar kelas serta tradisi dan perilaku warga sekolah secara kontinyu dan konsisten, sehingga tercipta budaya sekolah dalam lingkungan sekolah (Sahlan, 2009: 77-79).

Setiap anak terlahir di dunia ini adalah istimewa, dan membawa karakter yang berbeda-beda itu prinsipnya, baik anak-anak biasa ataupun Anak Berkebutuhan Khusus (ABK). Undang - undang menyatakan bahwa jika seorang anak memiliki kesulitan belajar yang secara signifikan lebih besar dari anak-anak lain susianya dalam menyelesaikan pekerjaan sekolah, juga dalam berkomunikasi dan berperilaku mereka dapat dikatakan memiliki kesulitan dalam belajar, istilah Anak Berkebutuhan Khusus(ABK) merujuk pada anak yang memiliki kesulitan atau ketidakmampuan belajar yang 
membuatnya lebih sulit untuk belajar dan mengakses pendidikan dibandingkan kebanyakan anak sesusianya (Thompson, 2010: 2).

Konsep anak berkebutuhan khusus (children with special needs) memiliki makna dan spektrum yang lebih luas dibandingkan dengan konsep anak luar biasa (exceptional children). Anak berkebutuhan khusus adalah anak yang secara pendidikan memerlukan layanan secara spesifik yang berbeda dengan anakanak pada umumnya. Anak berkebutuhan khusus ini memiliki apa yang disebut dengan hambatan belajar dan hambatan perkembangan (barrier to learning and development). Oleh sebab itu, mereka memerlukan layanan pendidikan yang sesuai dengan hambatan belajar dan hambatan perkembangan yang dialami oleh masing-masing anak. (Aphroditta, 2012: 47)

Pelaksanaan pembelajaran di SLB-PRI Pekalongan terutama di tingkat SMP dibagi masing-masing rombel, maksimal 8 anak setiap rombel. Adapun ketunaan yang ada di SLB-PRI Pekalongan yaitu tunagrahita sedang, tunawicara, tunarungu dan tunadaksa + tunagrahita. Di SLB-PRI Pekalongan ini melingkupi seluruh jenjang pendidikan, baik dari Sekolah Dasar (SDLB), Sekolah Menengah Pertama (SMPLB) dan Sekolah Menengah Atas (SMALB). Disini penulis mengfokuskan pada jenjang Pendidikan Sekolah Menengah Pertama, di SMPLB-PRI anak berkebutuhan khusus diklasifikasikan ada dua rombel yaitu anak Tunarungu (kelas B) dan anak Tunagrahita (kelas C). Sama seperti sekolah formal yang mayoritas anak didiknya normal di SMPLB juga diajarkan berbagai mata pelajaran. Terutama pendidikan Moral dan Agama, di SMPLB-PRI telah dilaksanakan pembiasaan budaya sekolah seperti 5S (senyum, sapa, salam, sopan dan santun), doa bersama (sebelum dan sesudah pelajaran), sholat dhuhur berjamaah, hafalan surat pendek, setiap hari besar diadakan kegiatan keagamaan (maulid nabi, isra miraj, dll) dan extrakurikuler (untuk menunjang ketrampilan ABK). Pembiasaan budaya sekolah di SLB dengan di sekolah formal yang membedakan adalah cara penyampaian dan implementasinya, respon anak berkebutuhan khusus ini ada yang merespon dengan baik dan ada yang merespon dengan 
kecenderungan sifat aktifnya (tidak bisa diam). Jika terjadi hal tersebut maka anak tunarungu-wicara akan dibantu menggunakan bantuan bahasa isyarat dan untuk anak tunagrahita akan dispesialkan (Nurrudin, 2019).

\section{Metode Penelitian}

Jenis penelitian yang digunakan adalah penelitian lapangan (field research). Penelitian lapangan adalah penelitian yang dilakukan dikancah atau tempat terjadinya gejala-gejala yang diselidiki (Moloeng, 2006: 5) Penelitian lapangan ini untuk mendiskripsikan implementasi metode pembiasaan berbasis budaya sekolah yang ada di SMPLB-PRI dalam meningkatkan karakter religius Anak Berkebutuhan Khusus melalui pengamatan lapangan, kemudian menganalisisnya dan berupaya melakukan teorisasi berdasarkan apa yang diamati. Penelitian ini menggunakan pendekatan penelitian kualitatif. Penelitian kualitatif merupakan penelitian khusus objek yang tidak dapat diteliti secara statistik atau cara kuantifikasi. (Basrowi, 2008: 1) Penelitian kualitatif biasanya digunakan meneliti peristiwa sosial, gejala ruhani dan proses tanda berdasarkan pendekatan nonpositivis. Penelitian ini menghasilkan data deskriptif berupa ucapan, tulisan dan perilaku orang-orang yang diamati. Melalui penelitian kualitatif peneliti dapat mengenali subjek dan merasakan pengalaman mereka (Ghoni, 2012: 13). Penelitian lapangan untuk mendiskripsikan implementasi metode pembiasaan berbasis budaya sekolah yang ada di SMPLB-PRI dalam meningkatkan karakter religius Anak Berkebutuhan Khusus yang nantinya akan menghasilkan kesimpulan-kesimpulan sehingga dapat bermanfaat bagi pihak terkait.

Sumber data primer adalah sumber data yang langsung memberikan data kepada pengumpul data. Dalam hal ini, data yang digunakan untuk mendapat informasi dari Kepala Sekolah, guru PAI, guru BK, wali kelas dan anak berkebutuhan khusus tentang implementasi dan hambatan metode pembiasaan berbasis budaya sekolah untuk meningkatkan karakter religius anak berkebutuhan khusus di SMPLB-PRI Pekalongan. Sumber data sekunder adalah 
sumber data yang tidak langsung memberikan data kepada pengumpul data (Sugiyono, 2016: 308-309) Dalam hal ini data yang digunakan yaitu berupa dokumen-dokumen, buku, jurnal dan wawancara dengan wali murid tentang implementasi dan hambatan metode pembiasaan berbasis budaya sekolah untuk meningkatkan karakter religius anak berkebutuhan khusus di SMPLB-PRI Pekalongan.

Dengan kata lain peneliti melakukan percakapan secara langsung yang berkaitan dengan penelitianya (wawancara kepala sekolah, guru mapel PAI dan wali kelas untuk mendapatkan informasi tentang bagaimana cara implementasi dan hambatan metode pembiasaan berbasis budaya sekolah untuk meningkatkan karakter religius anak berkebutuhan khusus di SMPLB PRI Pekalongan). Metode Observasi ini digunakan untuk memperoleh data yang berkaitan dengan implementasi dan hambatan metode pembiasaan berbasis budaya sekolah untuk meningkatkan karakter religius anak berkebutuhan khusus di SMPLB PRI Pekalongan Dalam penelitian ini berupa dokumen-dokumen (Dokumen pembelajaran, catatan observasi dari guru PAI dan wali kelas, absen sholat, jadwal solat berjamaah dan daftar hadir kegiatan keagamaan), gambar dan foto kegiatan belajar mengajar dan kegiatan lainya.

\section{Hasil Penelitian}

Istilah metode pembiasaan dapat diartikan sebuah cara yang dapat dilakukan untuk membiasakan anak didik berfikir, bersikap dan bertindak sesuai tuntunan ajaran Islam. Pembiasaan dinilai sangat efektif apabila penerapanya dilakukan terhadap peserta didik yang berusia kecil. Karena hal tersebut menjadi awal dalam proses pendidikan, maka pembiasaan merupakan cara yang sangat efektif dalam menanamkan nilai-nilai moral ke dalam jiwa anak (Arief, 2012: 114). Sedangkan pengertian budaya sekolah menurut Barnawi dan Mohammad Arifin budaya dapat diartikan sebagai sekumpulan nilai, keyakinan dan pemahaman dan norma yang dibagi bersama oleh anggota suatu organisasi (Barnawi, 2013: 108-110). 
Budaya sekolah sudah menjadi pembiasaan yang selalu diterapkan pada setiap sekolah. Tak terkecuali di SMPLB-PRI, tidak ada pengecualian untuk anak berkebutuhan khusus. Oleh karena itu berdasarkan data-data yang diperoleh peneliti bahwa model-model penciptaan budaya di SMPLB-PRI Pekalongan memiliki beberapa pembiasaan budaya sekolah yang berkaitan dengan peningkatan karakter religius anak berkebutuhan khusus sebagai berikut:

\section{Implementasi metode pembiasaan berbasis budaya sekolah untuk meningkatkan karakter religius anak berkebutuhan khusus di SMPLB-PRI Pekalongan yaitu melalui berbagai model :}

\section{Model Struktural}

Berdasarkan hasil wawancara dan observasi sebagaimana yang telah dijabarkan dalam bab tiga didapat hasil bahwa peraturan pembiasaan berbasis budaya sekolah keagamaan diterapkan di SMPLB-PRI Pekalongan, pihak sekolah telah memberikan pengarahan pada setiap tata tertib sekolah yang ada. Bapak Kamrin, S. Pd selaku kepala sekolah di SLB-PRI Pekalongan telah mencanangkan kebijakan pada pembiasaan keagamaan. Seperti anak berkebutuhan khusus diharuskan mampu membaca dan menghafal surat pendek, serta tertib dalam melaksanakan ibadah sholat dhuhur dan disiplin tepat waktu. Adapun peraturan kebijakan yang dapat membangun kesan anak berkebutuhan khusus dalam pembiasaan budaya sekolah seperti; Tepat waktu/ Disiplin, Menghafal doa-doa, dan Tertib.

Dari hasil penelitian diatas sesuai dengan teori yang dikemukakan oleh Anselmus JE Teonlie tentang peraturan pembiasaan budaya keagamaan. Peraturan keagamaan berfungsi mempersiapkan peserta didik menjadi anggota masyarakat yang memahami dan mengamalkan nilai-nilai ajaran agama. Peraturan keagamaan dapat diselenggarakan pada jalur pendidikan formal, nonformal dan informal (Teonlie: 100). 


\section{Model Formal}

Implementasi model formal budaya sekolah berupa pendidikan keagamaan dan pendidikan non keagamaan. Sholat dhuhur merupakan kewajiban bagi setiap muslim, oleh karena itu SMPLBPRI menerapkan sholat dhuhur berjamaah menjadi pembiasaan baik dalam rangka untuk meningkatkan kualitas keagamaan anak berkebutuhan khusus. Sholat dhuhur berjamaah dimulai sebelum anak-anak pulang sekolah agar menjadi pembiasaan dan menjadi contoh yang baik. Sholat berjamaah ini menjadi pembiasaan untuk anak SMPLB dan SMALB. Meskipun tidak terkecuali anak SDLB ikut melaksanakanya, sholat dhuhur berjamaah di imami oleh guru PAI baik oleh Pak Wafa (guru PAI SMP/SMALB) atapun oleh Pak Amsyad (guru PAI SDLB). Karakter religius yang dapat terbentuk antara lain karakter religius terhadap Tuhan, terhadap diri sendiri dan terhadap sesamanya. Adapun indikator dari karakter tersebut adalah anak memiliki sikap kebersamaan dengan teman, disiplin beribadah, takwa terhadap Tuhan dan rajin dalam beribadah.

Upacara bendera sudah menjadi pembiasaan di SMPLB-PRI, tidak hanya pembiasaan budaya sekolah upacara bendera setiap hari senin tetapi dihari-hari lainya seperti upacara memperingati hari kemerdekaan, hari kartini, hari pramuka,dll. Upacara bendera dilaksanakan pada pukul $07.30 \mathrm{WIB}$, petugas pelaksana upacara bendera oleh anak-anak berkebutuhan khusus dengan ketunaan khusus tunarungu. Berdasarkan hasil pengamatan beberapa guru menjadi pelatih sekaligus pemberi aba-aba pada saat berlangsungnya upacara, karena petugas upacara sebagian besar dari anak tunarungu guru pembimbing member bahasa isyarat agar petugas upacara tepat melaksanakan tugasnya. Implementasi upacara bendera dilakukan seperti upacara pada umumnya semua anak SDLB, SMPLB, SMALB, Kepala Sekolah, Guru dan Staff mengikuti upacara bendera. Karakter religius yang dapat muncul dalam implementasi budaya sekolah ini adalah karakter terhadap sesame dalam artian karakter terhadap teman, masyarakat dan bangsa. Didapat beberapa indikator dari pembiasaan tersebut anak 
memiliki rasa nasionalisme, sikap cinta tanah air, tertib, patuh aturan dalam pelaksanaan upacara dan jiwa pemimpin.

\section{Model Mekanik}

Senyum, sapa, salam, sopan dan santun atau yang biasa disebut 5S sudah menjadi pembiasaan di SMPLB-PRI Pekalongan. Anak berkebutuhan khusus melakukan interaksi tanpa melupakan prinsip $5 \mathrm{~S}$ tersebut. Berdasarkan pengamatan yang dilakukan anak berkebtuhan khusus selalu menerapkan senyum, sapa, salam, sopan dan santun. Selain 5S tersebut anak berkebutuhan khsusus dibiasakan melakukan pembiasaan salim setiap bertemu guru ataupun orang dewasa sebagai wujud penghormatan mereka. Dimana anak berkebutuhan khusus dengan temanya mereka biasa bergurau, menyapa dan bermain bersama yang menjadi wujud komunikasi mereka, dari hal tersebut dapat tercermin pembiasaan senyum, sapa dan salam. Sedangkan pembiasaan sapa dan salam tidak hanya mereka lakukan pada orang-orang yang dikenali saja dalam artian seperti teman, guru, orangtua dan staff tetapi, dengan orangasing yang baru mereka temui juga menerapkan prinsip tersebut. Pada saat peneliti melakukan observasi terlihat anak berkebutuhan khusus meminta bantuan kepada guru dalam kegiatan ketrampilan tangan, hal tersebut menjadi cermin implementasi pembiasaan sopan dan santun anak berkebutuhan khusus. Dari pembiasaan 5S ini karakter yang terbentuk adalah karakter terhadap keluarga dan sesama, dimana indikatornya yaitu hormat, ramah, menghargai oranglain serta penyayang.

\section{Model Organike}

Ketrampilan di SMPLB-PRI sudah menjadi pembiasaan budaya, karena dilakukan terus menerus untuk menunjang ketrampilan anak berkebutuhan khusus. Karena ABK tidak bisa hanya mengandalkan intelektualnya saja, harus ada ketrampilan lain. Ada berbagai macam ketrampilan yang sudah menjadi pembiasaan di SMPLB-PRI. Implementasi metode pebiasaan ketrampilan untuk anak berkebtuhan khusus di SMPLB-PRI dapat berjalan dengan 
baik. Di SLB-PRI Pekalongan setiap hari rabu, kamis dan jumat anak-anak dibiasakan mengikuti pelajaran ketrampilan, ada berbagai ketrampilan yang sudah berjalan di SLB-PRI untuk tingkat SMP ada ketrampilan tataboga, tatarias, musik, mencuci motor dan seni kriya atau kerajinan tangan. Pembagian kelas ketrampilan anak dibagi berdasarkan minat dan bakat masing-masing. Anak berkebutuhan khusus melakukan kegiatan penunjang aktif dan kreatif dibimbing oleh guru kelas SMPLB-PRI Pekalongan. Dari pembiasaan budaya sekolah ini didapat karakter yang terbentuk yaitu karakter terhadap diri sendiri, sesama dan lingkunganya dimana indikatornya adalah anak menjadi aktif, kreatif, terampil, dapat menghargai orang lain dan memiliki rasa hormat.

\section{Hambatan metode pembiasaan berbasis budaya sekolah untuk meningkatkan karakter religius anak berkebutuhan khusus di SMPLB-PRI Pekalongan}

Dalam implementasi kegiatan pembiasaan berbasis budaya sekolah pasti ada faktor pendukung dan penghambat, seperti dalam teori yang dikemukakan oleh Armai Arief tentang kelebihan dan kekurangan metode pembiasaan sebagaimana pendekatanpendekatan lainya dalam proses pedidikan, pendekatan pembiasaan tidak lepas dari dua aspek yang saling bertentangan yaitu kelebihan dan kekurangan:

Kelebihan Metode Pembiasaan, kelebihan pendekatan ini antara lain:

1. Dapat menghemat tenaga dan waktu dengan baik.

2. Pembiasaan tidak hanya berkaitan dengan lahiriyah aspek, tetapi juga berhubungan dengan aspek batiniah.

3. Pembiasaan dalam sejarah tercatat sebagai metode yang paling berhasil dalam pembentukan kepribadian anak didik.

Kekurangan Metode Pembiasaan, kelemahan metode ini adalah membutuhkan tenaga pendidik yang benar-benar dapat dijadikan sebagai contoh tauladan di dalam menamamkan sebuah nilai kepada anak didik. Oleh karena itu pendidikan yang dibutuhkan dalam menerapkan metode ini adalah pendidik yang dapat 
menyelesaikan antara perkataan dan perbuatan, sehingga tidak hanya mampu memberikan nilai tetapi juga mampu mengamalkan nilai yang diajarkan terhadap anak didik (Arief, 2012: 114-116).

Dari teori diatas peneliti akan membahas kekurangan atau hambatan dari metode pembiasaan berbasis budaya sekolah dalam meningkatkan karakter religius anak berkebtuhan khusus dalam dua faktor yaitu faktor internal dan faktor eksternal dalam implementasi metode pembiasaan budaya sekolah dalam meningkatkan karakter religius anak berkebutuhan khusus di SMPLB-PRI Pekalongan, didapat hasil sebagai berikut :

\section{Faktor Internal}

Faktor internal atau faktor dari dalam diri anak berkebutuhan khsuus dapat menghambat berjalanya pembiasaan budaya sekolah di SMPLB-PRI Pekalongan. Berdasarkan observasi dan wawancara peneliti menemukan beberapa faktor internal penghambat pembiasaan sebagai berikut:

1. Anak sulit memahami karena IQ dibawah rata-rata.

2. Sulit mengatur anak / anak sangat aktif di dalam kelas

3. Kurangya kesadaran beribadah

4. Pelatihan lebih untuk setiap kegiatan pembiasaan budaya sekolah

5. Butuh proses yang cukup lama dalam melatih anak membiasakan budaya sekolah.

Faktor internal lebih menitikberatkan pada anak berkebutuhan khusus. Salah satunya lemahnya daya ingat atau IQ dibawah ratarata, yang dapat menghambat proses berjalanya pembiasaan budaya sekolah. Seperti pembiasaan budaya sekolah berdoa, mengaji dan menghafal yang membutuhkan kekuatan daya ingat, sementara anak SLB lemah akan hal itu. Kemudian seperti pembiasaan upacara bendera anak-anak sulit untuk fokus dan tetap diam disiplin, kedisiplinan mereka hanya sebatas mau ikut upacara bendera meskipun tetap bergurau dan tidak bisa diam ditempat.

Anak berkebutuhan khusus lebih sering meminta bantuan gurunya dalam membantu setiap kegiatan pembiasan, Karena 
keterbatasan gerak dan fungsi otak mereka menjadi poin kelemahan dalam implementasi pembiasaan berbasis budaya sekolah ini. Dengan kata lain hambatan implementasi budaya sekolah lebih ke faktor anak berkebutuhan khusus yang tidak mampu memahami dan dengan terbatasnya gerak anak berkebutuhan khusus.

\section{Faktor Eksternal}

Jadi dapat dipahami faktor penghambat berjalanya metode pembiasaan ini tidak hanya dari anak berkebutuhan khusus saja, tetapi peran guru dan orangtua serta sarana prasarana juga ikut andil dalam pembiasaan budaya sekolah ini. Bagaimana akan terlaksana jika kesadaran guru dan orangtuanya serta sarana prasarana kurang begitu mendukung budaya sekolah ini. Karena orangtua merupakan madrasah pertama bagi anak, maka karakter religius anak berkebutuhan khusus dapat dibentuk melalui dukungan orang tua. Serta bimbingan dari guru dan fasilitas dari sarana prasarana sekolah.

\section{Catatan Akhir}

Dari hasil penelitian bahwa implementasi metode pembiasaan berbasis budaya sekolah untuk anak berkebutuhan khusus di SMPLB-PRI Pekalongan terdapat empat model pembiasaan budaya sekolah. (1) Model Struktural didasari oleh peraturan dan pembangunan kesan dalam peraturan keagamaan dan non keagamaan. (2) Model Formal berupa pembiasaan budaya keagamaan seperti doa bersama, mengaji, hafalan surat dan sholat berjamaah, budaya non keagamaan yaitu upacara bendera. (3) Model mekanik yaitu penanaman sikap afektif implementasinya dalam pembiasaan 5S. (4) Model organik yaitu penanaman psikomotorik dalam kegiatan KTK atau ketrampilan. Dari implementasi keempat model pembiasaan tersebut dapat meningkatkan karakter religius terhadap Tuhan, diri sendiri, keluarga, sesama dan lingkungan sekitar. Adapun yang menjadi faktor penghambat yaitu (1) faktor internal dari kekurangan anak berkebutuhan khusus (IQ dibawah rata-rata sehingga menghambat 
implementasi pembiasaan budaya sekolah). (2) Faktor eksternal dari faktor sarana prasarana, kurangnya dukungan orangtua dan guru.

\section{Daftar Pustaka}

Aphroditta M. 2012. Panduan Lengkap Orangtua \& Guru Untuk Anak Dengan Disgrafia (Kesulitan Menulis). Yogyakarta: Javalitera.

Arief, Armai. 2002. Pengantar Ilmu Dan Metodologi Pendidikan Islam. Jakarta: Ciputat Press.

Barnawi Dan Mohammad Arifin. 2013. Branded School Membangun Sekolah Unggul Berbasis Peningkatan Mutu. Jogjakarta: Ar-Ruzz Media.

Basrowi Dan Suwandi. 2008. Memahami Penelitian Kualitatif. Jakarta: Rineka.

Ghoni, M. Djunaidi Dan Fauzan Almanshur. 2012. Metodologi Penelitian Kualitatif. Jogjakarta: Ar-Ruzz Media.

Moloeng, Lexy J. 2006. Metodologi Penelitian Kualitatif. Bandung: Remaja Rosdakarya.

Nurrudin. 2019. "Implementasi Program Pembiasaan Berbasis Budaya Sekolah Di SMPLB-Pri Pekalongan". Wawancara Dengan Guru Pendidikan Agama Islam DI SMPLB-Pri Pekalongan, 14 Januari 2019.

Sahlan, Asmaun. 2009. Mewrijudkan Budaya Religius Di Sekolah. UIN: Maliki Press.

Sugiyono. 2016. Metode Penelitian Pendidikan Pendekatan Kuantitatif, Kualitatif Dan R\&D) Cet Ke-23. Bandung: Alfabeta.

Thompson, Jenny. 2010. Memahami Anak Berkebutuban Khusus. Indonesia: Erlangga. 